\title{
SENSIBILIDADE À DESSECAÇÃO E AOARMAZENAMENTO EM SEMENTES DE Eugenia pyriformis Cambess. (UVAIA) ${ }^{1}$
}

\author{
SILVANA DE PAULA QUINTÃO SCALON, ${ }^{2}$, ELIANE MARQUES DA SILVA NEVES ${ }^{3}$, \\ TATHIANA ELISA MASETO ${ }^{4}$,ZEFA VALDIVINA PEREIRA ${ }^{2}$
}

RESUMO - Objetivou-se com este trabalho avaliar a sensibilidade à dessecação e a longevidade durante o armazenamento de sementes de Eugenia pyriformis Cambess. (uvaia). Os frutos utilizados foram coletados em matrizes localizadas na cidade de Amambai-MS. Para o estudo da sensibilidade à dessecação, foi utilizado o protocolo baseado na redução do nível de hidratação das sementes a cada cinco pontos percentuais, obtendo-se sementes com teores de água de $45 ; 40 ; 30 ; 25 ; 20 ; 15 ; 10$ e 5\%. Para estudar a longevidade das sementes durante o armazenamento, foram testadas as condições de câmara fria e seca ( $\left.16 \pm 1 \mathrm{C}^{\mathrm{o}} / 40 \% \mathrm{UR}\right)$, geladeira $\left(5 \pm 1 \mathrm{C}^{\circ}\right)$ e freezer $\left(-18 \pm 1^{\circ} \mathrm{C}\right)$ durante 30 dias, e as sementes que não foram submetidas ao armazenamento constituíram o tratamento-controle. A semeadura foi realizada entre areia a $20 / 30^{\circ} \mathrm{C} \mathrm{com} 10 \mathrm{~h}$ de luz/14h de escuro em B.O.D. As sementes de uvaia são sensíveis à dessecação e não toleraram a secagem a $5 \%$ de teor de água. As sementes recém-beneficiadas apresentaram germinação de aproximadamente $77 \% \mathrm{e}$ com a secagem até $5 \%$ houve a redução para $15 \%$ de germinação. A diminuição do teor de água provocou a redução da massa fresca, comprimento de raiz primária, hipocótilo e total de plântulas e tempo médio de germinação. As condições de armazenamento sob temperaturas baixas e a secagem reduziram a germinação das sementes, indicando assim o comportamento recalcitrante das sementes de uvaia.

Termos para indexação: Cerrado, germinação de sementes, longevidade, Myrtaceae, recalcitrância.

\section{DESICCATION SENSIVITY AND STORAGE IN Eugenia pyriformis Cambess. SEEDS (UVAIA)}

\begin{abstract}
This study aimed to evaluate the desiccation sensivity and storage and longevity behavior of uvaia seeds (Eugenia pyriformis Camb.). It was carried out with seeds from fruits collected at Amambai-MS city. To study the desiccation sensitivity, a protocol based on the dehydration level on each five percentage points reaching $45,40,30,25,20,15,10$ and $5 \%$ seeds moisture contents was used. To study the longevity of seeds during storage were tested the following conditions of cold and dry chamber $\left(16 \pm 1 \mathrm{C}^{\circ} / 40 \%\right.$ UR), refrigerator $\left(5 \pm 1 \mathrm{C}^{\circ}\right)$ and freezer $\left(-18 \pm 1^{\circ} \mathrm{C}\right)$ for 30 days and seeds sown soon after processing constituted the control treatment. Seeds were sowed between sand at $20 / 30^{\circ} \mathrm{C}$ at $10 \mathrm{~h} \mathrm{light} / 14 \mathrm{~h}$ darkness in B.O.D. Uvaia seeds are desiccation sensitivity and can not tolerate drying below $5 \%$ moisture content. The moisture content decrease caused the reduction on the fresh mass, primary root length, hypocotyls length and on the seedlings total length reduction as in the germination medium time. The fresh seeds presented approximately $77 \%$ germination and the $5 \%$ moisture content dehydration reduced the germination to $15 \%$. The storage conditions under low temperatures and seeds dehydration reduced seed germination, thus indicating a recalcitrant behavior of uvaia seeds.
\end{abstract}

Index terms: Savannah, seeds germination, longevity, Myrtaceae, recalcitrance.

1(Trabalho 174-11). Recebido em: 06-06-2011. Aceito para publicação em: 11-10-2011.

${ }^{2}$ Bióloga, Prof'. Dr ${ }^{\mathrm{a}}$. adjunta da Universidade Federal da Grande Dourados/FCA, bolsista de produtividade em pesquisa pelo CNPq. Rodovia Dourados-Itahum, Km 12, CEP. 79804-970. Dourados-MS. E-mails: silvanascalon@ufgd.edu.br; zefapereira@ufgd.edu.br ${ }^{3}$ Bióloga, Mestranda em Agronomia/Produção Vegetal, UFGD/FCA. CEP. 79804-970. Dourados-MS. E-mail: elianemarques@bol.com.br ${ }^{4}$ Engenheira agrônoma, Prof ${ }^{a}$. visitante da Universidade Federal da Grande Dourados/FCA. E-mail: tathianamasetto@ufgd.edu.br 


\section{INTRODUÇÃO}

A flora do Cerrado apresenta grande biodiversidade. No Mato Grosso do Sul, o Cerrado abriga vários grupos de espécies, dentre as quais, representantes da família Myrtaceae que podem ser utilizados de forma ornamental ou na produção comercial na fruticultura regional, devido à qualidade dos frutos. $\mathrm{O}$ gênero Eugenia está entre os mais importantes dessa família, apresentando mais de 3.000 espécies, sendo que a maioria das nativas brasileiras possui frutos comestíveis (DONADIO; MORO, 2004; BARBEDO et al., 2005; VENDRAME; SILVA et al., 2005).

A maioria das espécies de Eugenia nativas do Brasil produzem poucas sementes em seus frutos, geralmente uma ou duas, o que dificulta a produção de mudas em escala comercial (VENDRAME; SILVA et. al., 2005). Diante da falta de informações sobre a propagação assexuada dessas espécies e o potencial econômico que elas representam, torna-se importante o uso de tecnologias que permitam maximizar o uso das sementes.

A Eugenia pyriformis Cambess., popularmente conhecida como uvaia, uvaieira, uvalha, uvalheira, é uma espécie de hábito arbóreo que mede aproximadamente de 5 a $15 \mathrm{~m}$ de altura, possui frutos indeiscentes, carnosos, piriformes, pilosos, com coloração amarela, comestíveis, de sabor adocicado e acidulado, podendo ser utilizados na fabricação de sucos, vinagre e vinho. As sementes apresentam tegumento de coloração castanha, cotilédones carnosos e justapostos, e após a extração, essas oxidam-se rapidamente e escurecem, sendo consideradas sensíveis à dessecação (ANDRADE; FERREIRA, 2000; DELGADO; BARBEDO, 2007).

Para programas de repovoamento de vegetação ou para a manutenção dos bancos de germoplasma, a qualidade fisiológica das sementes deve ser preservada até sua semeadura, permitindo o uso de espécies vegetais em épocas e locais diferentes aos de sua origem (KOHOMA et al., 2006; YUYUAMA et al., 2011). Assim, estudos relacionados à tolerância à dessecação de sementes são importantes para a conservação ex situ do germoplasma de espécies frutíferas nativas do Cerrado e para indicar o grau de umidade para o armazenamento eficiente das sementes, sem causar danos à qualidade fisiológica e ao sucesso da propagação futura da espécie.

Diante da importância da espécie e da carência de informações sobre sua conservação, objetivou-se com este trabalho estudar a sensibilidade à dessecação e a longevidade das sementes de uvaia durante o armazenamento.

\section{MATERIAL E MÉTODOS}

Os frutos de Eugenia pyriformis Cambess. (uvaia) foram coletados diretamente de 8 matrizes localizadas a $5 \mathrm{~km}$ da cidade de Amambai, situada na porção sul do Estado de Mato Grosso do Sul, entre as coordenadas geográficas S 2302'37' e W 5509'10" (Mato Grosso do Sul, 1990), na segunda quinzena de outubro de 2009. Após a coleta, os frutos foram beneficiados sob água corrente até a despolpa. Após a separação das sementes dos resíduos dos frutos, estas permaneceram em camada única sobre papel no interior de bandejas plásticas até que o excesso de água fosse removido. As sementes foram homogeneizadas compondo um único lote.

Para a determinação do teor de água das sementes após o beneficiamento, foi utilizado o método da estufa a $105 \pm 3^{\circ} \mathrm{C}$, durante 24 horas, conforme as Regras para Análise de Sementes (BRASIL, 2009). As sementes utilizadas foram cortadas ao meio, e os resultados foram expressos em percentagem, baseados no peso das sementes úmidas. Para o teste de germinação, as sementes recém-extraídas dos frutos foram lavadas em solução de hipoclorito de sódio a $1 \%$, durante 5 minutos, e em seguida, semeadas entre areia no interior de bandejas plásticas, sob temperatura alternada de $20 / 30^{\circ} \mathrm{C}$, com 10 horas de luz para a temperatura mais elevada e 14 horas de escuro para a temperatura mais baixa em B.O.D., mantendo-se a umidade do substrato durante o período. Com o material coletado, foram realizados dois experimentos no Laboratório de Sementes da Faculdade de Ciências Agrárias da Universidade Federal da Grande Dourados.

Experimento I - Sensibilidade à dessecação: para avaliar a capacidade de tolerância à dessecação, foi utilizado o protocolo baseado na redução do nível de hidratação das sementes a cada cinco pontos percentuais (HONG; ELLIS, 1996). Para a obtenção dos tratamentos, as sementes recém-beneficiadas foram divididas em sub-amostras e foram submetidas a secagem lenta sob temperatura de ambiente de laboratório $\left(25 \pm 1^{\circ} \mathrm{C} / 50 \%\right.$ UR), de acordo com os níveis de hidratação a serem obtidos $(45 ; 40$; $30 ; 25 ; 20 ; 15 ; 10$ e $5 \%$ de teor de água) por meio de pesagens sucessivas até que o peso encontrado coincidisse com o teor de água desejado, por meio da expressão proposta por Cromarty et al. (1985). O tempo necessário para alcançar os teores desejados de água das sementes foi avaliado.

Ao alcançar o grau de umidade preestabelecido para cada tratamento, as sementes foram retiradas das bandejas plásticas, lavadas com solução de hipoclorito de sódio a $1 \%$, para desinfestação, e semeadas 
de acordo com a metodologia citada anteriormente.

Experimento II - Longevidade durante o armazenamento: de acordo com os resultados do experimento I, as sementes com teor de água de $30 \%$ foram acondicionadas em sacos plásticos transparentes com espessura de $0,25 \mathrm{~mm}$, e foram testadas as seguintes condições de armazenamento: câmara fria e seca $\left(16 \pm 1^{\circ} \mathrm{C} / 40 \% \mathrm{UR}\right)$, geladeira $\left(5 \pm 1^{\circ} \mathrm{C}\right)$ e freezer $\left(-18 \pm 1^{\circ} \mathrm{C}\right)$, todos em ausência de luz. As sementes que não foram armazenadas constituíram o controle. Após 30 dias de armazenamento, determinou-se o teor de água das sementes e foi realizada a semeadura conforme metodologia citada anteriormente.

Em ambos os experimentos, foram avaliados: Germinação: após a retirada das sementes do substrato, foram consideradas germinadas aquelas que apresentavam protrusão da raiz primária com mais de $5 \mathrm{~mm}$ de comprimento, e os resultados, expressos em porcentagem. Comprimento de plântulas: obtido por meio das medidas do comprimento da raiz primária, do hipocótilo e do comprimento total das plântulas, com auxílio de régua, e os resultados, expressos em centímetros. Massa fresca: obtida através da pesagem das plântulas em balança analítica e cujos resultados foram expressos em gramas. Tempo médio de germinação: por meio do número de sementes germinadas em cada repetição, a cada avaliação realizada. Para estimar o tempo médio de germinação (TMG), foi utilizada a equação de Edmond e Drapalla (1965), citado por Ranal e Santana (2006), pela qual se obteve o índice que representa a média do tempo necessário para germinação (expressos em dias).

Em ambos os experimentos, as avaliações foram realizadas semanalmente, durante 90 dias. O delineamento experimental adotado foi o inteiramente casualizado, com quatro repetições de 25 sementes cada. Após testar a normalidade dos resíduos e a homogeneidade entre as variâncias, os dados foram submetidos à análise de variância e, quando significativas, foram realizadas análise de regressão (para avaliação da tolerância à dessecação) e teste de Tukey (para avaliar o armazenamento das sementes), ambos a $5 \%$ de probabilidade.

\section{RESULTADOS E DISCUSSÃO}

\section{Sensibilidade à dessecação}

As sementes de uvaia apresentaram teor de água inicial elevado após o beneficiamento $(45 \%)$, fato observado também em sementes de outras espécies de Eugenia, como em sementes de E. uniflora L. (52\%), E. brasiliensis Lam.(49,6\% a 47,2\%), E. involucrata DC. (58,2\%), E. pyriformis Camb. $(66,8 \%)$
E. umbelliflora Berg.(42,5\%), E. cerasiflora Miq. $(62,8 \%)$ (DELGADO; BARBEDO, 2007) e E. pleurantha O. Berg. (35,5\%) (MASETTO et al., 2008).

Esses valores elevados de teor de água das sementes na maturidade, geralmente, estão associados à sensibilidade à dessecação. Sementes que apresentam essa característica possuem curta longevidade, principalmente em condições de baixa temperatura e elevada umidade relativa do ar. O período é variável entre espécies, sendo que a intolerância à dessecação pode estar associada a vários compostos e processos, como o acúmulo de reservas insolúveis, a presença de sistema antioxidante eficiente, o acúmulo de proteínas e açúcares, e a presença de um sistema de reparo eficiente durante a reidratação (PAMMENTER; BERJAK, 1999; LEONHARDT et al., 2010).

As sementes apresentaram secagem lenta, sendo que o período necessário para atingir teores de 40 e $30 \%$ de água foi de 1 e 4 dias, respectivamente; e para os demais teores, foi necessário um tempo mais longo (Figura 1). Para avaliar o limite de tolerância à dessecação das sementes, é importante observar a velocidade da secagem, sendo que a secagem rápida de todas as espécies estudadas por Delgado e Barbedo (2007) prejudicou a germinabilidade e a produção de plântulas normais, independentemente do método utilizado. Portanto, a secagem lenta utilizada neste estudo pode ter causado efeito menos prejudicial às sementes de uvaia.

Em trabalhos realizados por Justo et al. (2007) com sementes de uvaia, a secagem branda estimulou o metabolismo da semente com respostas ultraestruturias similares à diferenciação celular que ocorre durante a germinação. Os autores observaram que, nos tratamentos de secagem mais branda (16 e 72 horas a $20^{\circ} \mathrm{C}$ e 16 horas a $35^{\circ} \mathrm{C}$ ), o conteúdo de água das sementes reduziu pouco em relação ao conteúdo inicial, e os danos ultraestruturais foram menores em comparação à secagem por 72 horas a $35^{\circ} \mathrm{C}$. Esses autores sugeriram que a secagem e o armazenamento prolongado devem ser evitados em sementes dessa espécie.

A porcentagem de germinação das sementes foi afetada pela dessecação e verificou-se ajuste de regressão para a germinação de uvaia conforme a redução do teor de água das sementes (Figura 2 a).

A massa fresca e o comprimento total de plântulas (Figuras 2b e 2e, respectivamente) também foram influenciados negativamente pela dessecação das sementes, sendo também observado ajuste de regressão para essas características, assim como para o comprimento de raíz primária, que apresentou redução linear conforme a diminuição do nível de hidratação das sementes (Figura 2c). Não foram 
observados ajustes de regressão para os níveis de hidratação sobre o comprimento de hipocótilo (Figura 2d) e tempo médio de germinação das sementes (Figura 2f), que variaram em torno de 2,71 cm e 60 dias, respectivamente.

Resultados semelhantes foram observados em estudos realizados com sementes de seis espécies de Eugenia, sendo possível verificar diferenças na sensibilidade à perda de água, permitindo identificar três grupos distintos. As mais sensíveis à dessecação foram as sementes de E. pyriformis, que apresentaram início de perda de viabilidade com teor de água superior e próximo a $65 \%$, e o teor de água letal foi de $15 \%$. Sementes de E. uniflora, E. brasiliensis e E. involucrata apresentaram-se como sementes moderadamente sensíveis à dessecação, com início da perda de viabilidade com teores de água próximos de $45-50 \%$. As sementes de E. umbelliflora e E. cerasiflora formaram o grupo das sementes menos sensíveis com início da perda da viabilidade com teores de água em torno de 45\% (DELGADO; BARBEDO, 2007).

$\mathrm{Na}$ maioria dos casos, as sementes recalcitrantes perdem a viabilidade com a secagem até atingir o nível de hidratação 3 (20 a 33\% de teor de água), quando estão metabolicamente ativas e com as membranas hidratadas e, provavelmente nesse nível, ocorre desordem no metabolismo, e os mecanismos de reparo tornam-se menos eficientes (MARCOS FILHO, 2005).

3.De acordo com Andrade e Ferreira (2000), sementes de uvaia apresentaram sensibilidade à dessecação e perderam a viabilidade quando o grau de umidade atingiu valores inferiores a $14 \%$ e o processo de germinação é relativamente lento e desuniforme, podendo estender-se até 135 dias.

Dessa forma, o presente estudo sugere que sementes de uvaia apresentaram comportamento recalcitrante quanto à tolerância à dessecação, verificado pela redução da germinação das sementes com teor de água abaixo de 30\%. De acordo com Berjak e Pammenter (2008), as sementes recalcitrantes não toleram a perda de água e sofrem danos em diferentes níveis durante a secagem e o armazenamento.

\section{Armazenamento}

Após os 30 dias de armazenamento em câmara fria e seca, em geladeira e em freezer, as sementes apresentaram teores de água de 30\%, 25\% e $23 \%$, respectivamente. Resultados semelhantes foram verificados por Andrade e Ferreira (2000), com sementes de uvaia, em que as condições de câmara fria também mantiveram o teor de água das sementes em níveis superiores a $20 \%$ durante 60 dias de armazenamento.

As sementes armazenadas em freezer não germinaram, sugerindo que são intolerantes ao congelamento, enquanto, nas demais condições de armazenamento, não houve diferença significativa na porcentagem de germinação. Sementes recém-beneficiadas (controle) apresentaram germinação inicial de $57 \%$, sendo verificada uma redução na germinação de aproximadamente 17 pontos percentuais em sementes armazenadas em geladeira com $41 \%$ de germinação e sementes armazenadas em câmara fria e seca que apresentaram 39\% de germinação (Figura 3a).

Andrade e Ferreira (2000) observaram que sementes de uvaia, armazenadas em câmara fria e seca, apresentaram redução gradativa e significativa do teor de água, gerando efeito significativo na emergência das plântulas, proporcionando uma redução da emergência inferior a $50 \%$ da emergência inicial.

O mesmo comportamento da porcentagem de germinação foi observado para massa fresca, comprimento de raiz primária, comprimento de hipocótilo e comprimento total de plântulas, que também não variaram significativamente entre os ambientes de armazenamento em câmara fria e seca, geladeira e o controle (Figuras 3a, c , d, e, f).

As sementes de uvaia armazenadas em freezer não germinaram. Em revisão realizada por Hellmann et al. (2006), os autores relataram que existem espécies que não toleram grande redução de temperatura, principalmente o congelamento. Nestas condições, a água contida nas sementes pode propiciar a formação de cristais de gelo, acarretando rupturas mecânicas na parede celular e no sistema de membranas, o que pode promover a desagregação celular e a consequente perda da viabilidade das sementes.

Houve efeito significativo das condições de armazenamento para o tempo médio de germinação (Figura 3b), que foi menor nas sementes de uvaia armazenadas em câmara fria e seca (40 dias), comparado ao tempo de germinação das sementes armazenadas em geladeira (60 dias) e para sementes que não foram armazenadas (66 dias).

Embora as condições de armazenamento tenham reduzido a capacidade de germinação e as características de crescimento, parece ter ocorrido a minimização de dormência das sementes de uvaia, evidenciado pela redução no tempo médio de germinação das sementes.

Scalon et al. (2004) observaram que sementes de uvaia apresentaram maior porcentagem de emergência quando permaneceram armazenadas por 60 dias sob refrigeração $(65,56 \%)$ e por 90 dias sob temperatura ambiente $(52,03 \%)$, em comparação com as sementes recém-beneficiadas, as quais não 
germinaram imediatamente após a extração dos frutos. Masetto et al. (2008) observaram o aumento da porcentagem de germinação de E. pleurantha após o armazenamento em câmara fria e seca durante 60 dias. De acordo com Barroso (2002), o embrião de espécies do gênero Eugenia é globoso, sem diferenciação aparente entre o eixo embrionário e os cotilédones; além disso, considera-se o embrião conferruminado, ou seja, sem distinção da linha de soldadura entre os cotilédones.

Possivelmente, os resultados do presente trabalho podem estar associados a essas indicações, sugerindo a existência de dormência morfológica em sementes de uvaia que pode ter sido superada pelo armazenamento.
Estudos sobre o comportamento de sementes durante $\mathrm{o}$ armazenamento demonstraram que sementes de diversas espécies de Myrtaceae (Calyptranthes lúcida Mart., E. handroana D. Legrand, E. brasiliensis, E. dysenterica DC. e Myrciaria dubia (H.B.K) McVaugh) (CARVALHO et al., 2006; YUYAMA et al., 2011) apresentaram comportamento recalcitrante, o que pode indicar uma tendência de que grande parte das espécies pertencentes a essa família apresenta sementes com sensibilidade à dessecação e ao armazenamento. Essa informação é importante para os trabalhos de conservação de sementes de espécies frutíferas nativas e é necessário salientar que, a partir desses conhecimentos, é possível adotar procedimentos corretos para colheita, transporte e beneficiamento das sementes.

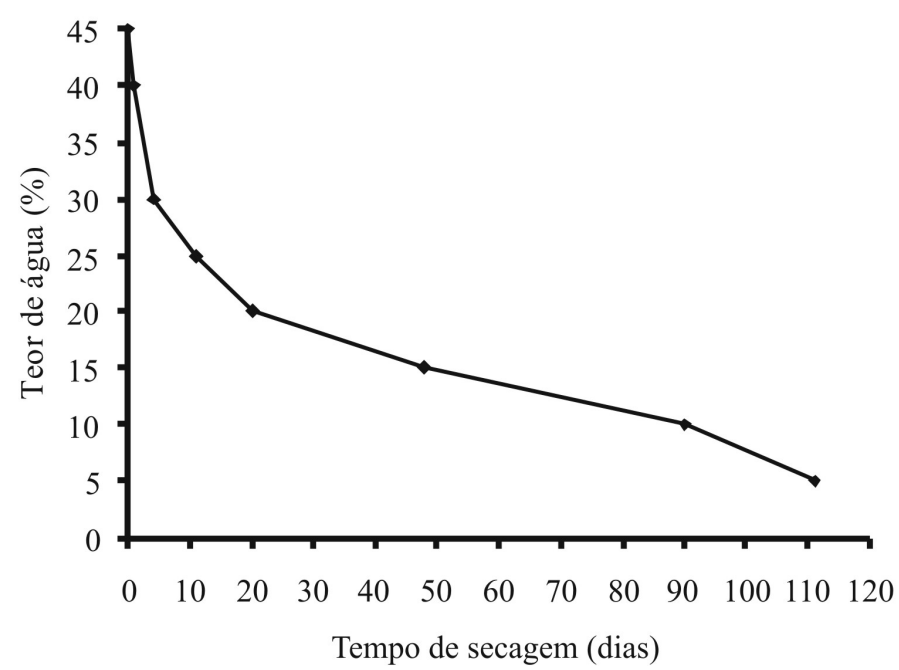

FIGURA 1 - Tempo de secagem (dias) em função do teor de água (\%), em sementes de Eugenia pyriformis Cambess.
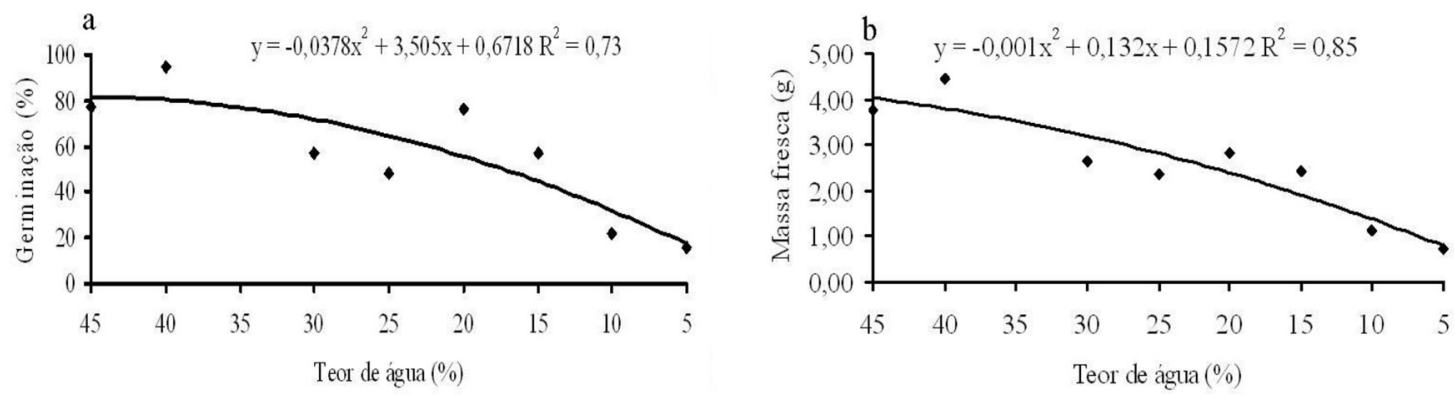

continua... 
continuação...
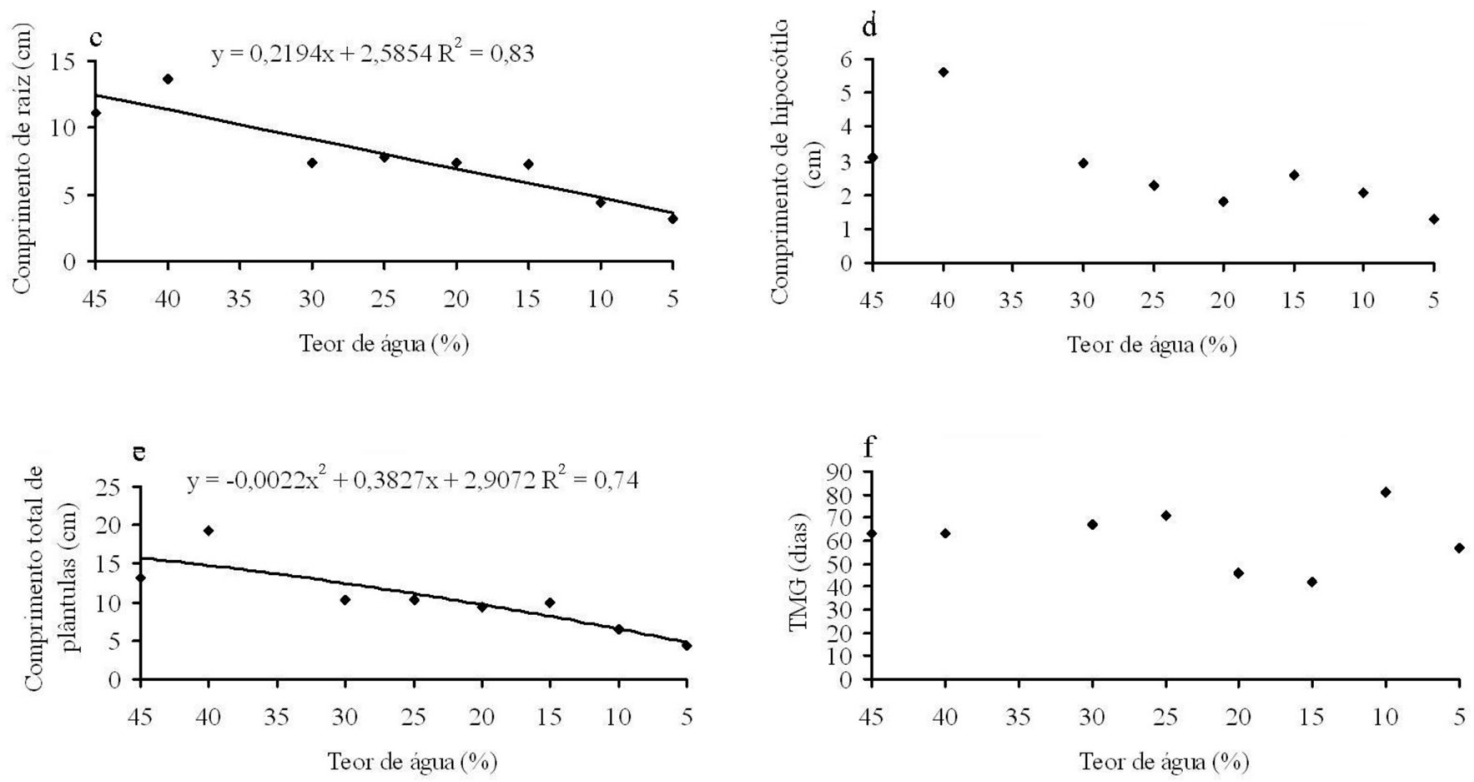

FIGURA 2 - a . Germinação (\%); b. Massa fresca (g); c. Comprimento de raiz primária (cm); d. Comprimento de hipocótilo $(\mathrm{cm})$; e. Comprimento total de plântulas $(\mathrm{cm})$; f. Tempo médio de germinação (dias) em função do teor de água nas sementes de Eugenia pyriformis Cambess.
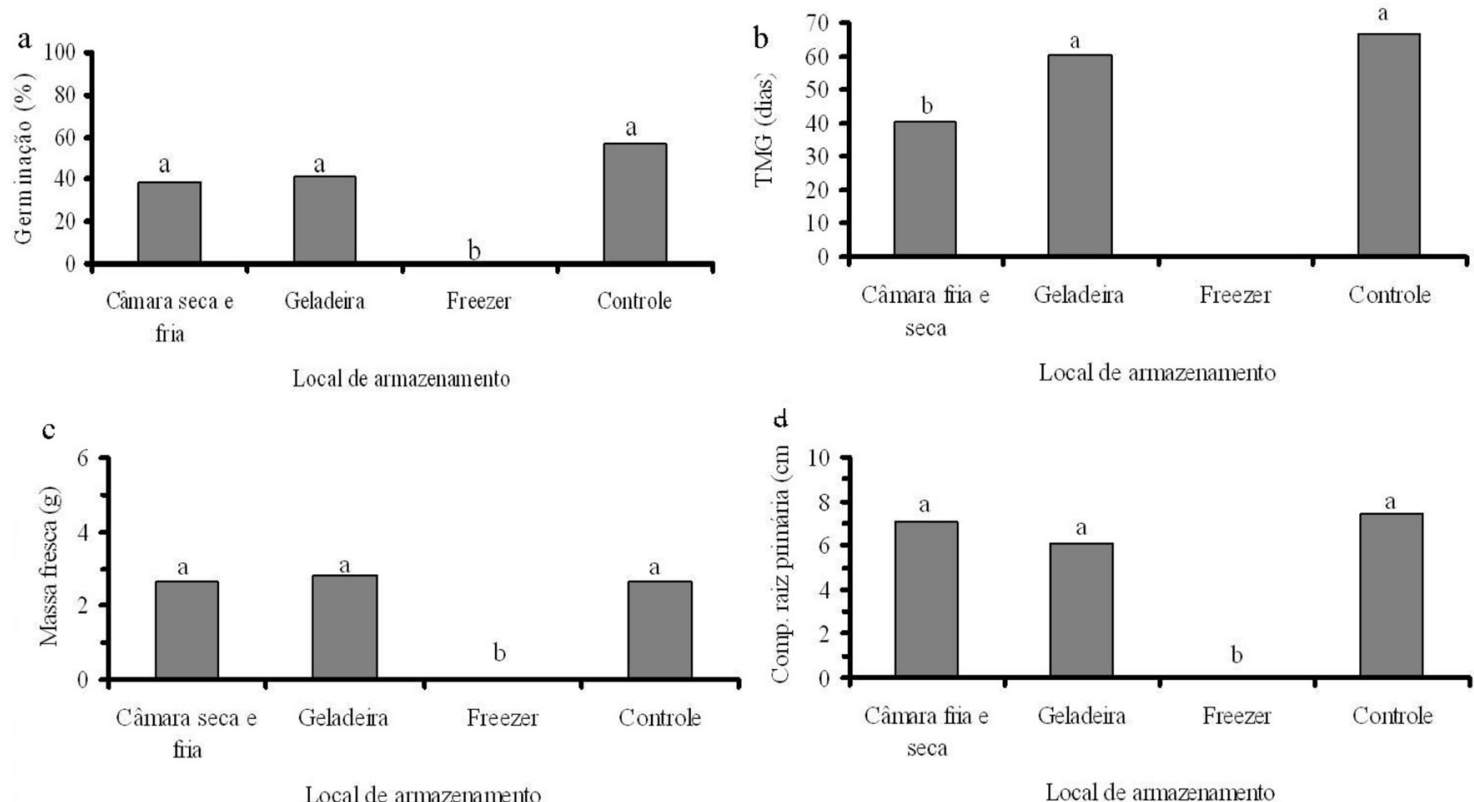

continua... 
continuação...
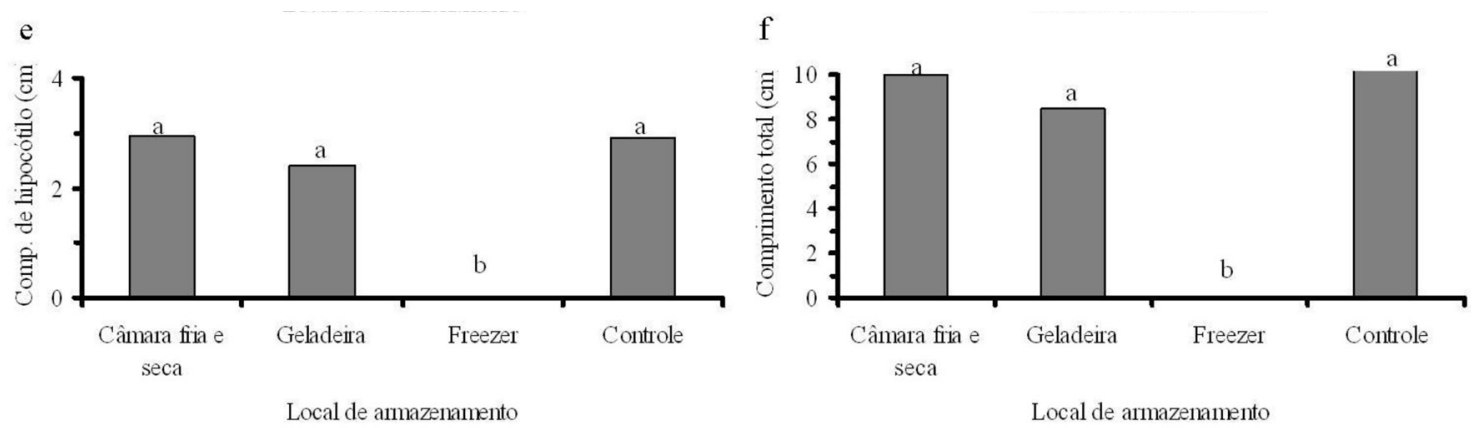

FIGURA 3 - a. Germinação (\%); b. Tempo médio de germinação (TMG) (dias); c. Massa fresca (g); d. Comprimento de raiz primária $(\mathrm{cm})$; e. Comprimento de hipocótilo $(\mathrm{cm})$; f. Comprimento total em função do local de armazenamento durante 30 dias de sementes de Eugenia pyriformis Cambess.

\section{CONCLUSÕES}

1-Sementes de uvaia são sensíveis à dessecação, e a redução do teor de água a partir de $30 \%$ prejudica a qualidade fisiológica das sementes.

2-As condições de armazenamento em freezer e a secagem reduzem a viabilidade, indicando assim um comportamento recalcitrante das sementes.

3-O armazenamento em câmara fria e seca reduz o tempo médio de germinação das sementes.

\section{REFERÊNCIAS}

ANDRADE, R.N.B.; FERREIRA, A.G. Germinação e Armazenamento de sementes de uvaia (Eugenia pyriformis Camb.) Myrtaceae. Revista Brasileira de Sementes, Pelotas, v.22, n. 2, p 118 - 125, 2000.

BARBEDO, A.S.C.; BIANCHI, C.G.; KELLER, L.R.; ORTEGA, M.G.; ORTEGA, S.E.H. Manual técnico de arborização urbana. 2.ed. São Paulo: PMSP-SVMA, 2005. 45 p.

BRASIL. Ministério da Agricultura e da Reforma Agrária. Regras para análises de sementes. Brasília: SNDA/DNDV/CLAV, 2009. 365p.

BARROSO, G.M. Sistemática de angiospermas do Brasil. 2. ed. Viçosa: Universidade Federal de Viçosa, 2002.
BERJAK, P.; PAMMENTER, N.W. From Avicennia to \izania: seed recalcitrance in perspective. Annals of Botany, Oxford, v. 101, p.213-228, 2008.

CARVALHO, L.R.; SILVA, E.A.A.; DAVIDE, A.C. Classificação de sementes florestais quanto ao comportamento no armazenamento. Revista Brasileira de Sementes, Pelotas, v.28, n.2, p. 15- 25, 2006.

CROMARTY, A.S.; ELLIS, R.H.; ROBERTS, E.H. Desing of seed storage facilities for genetic conservartion. Rome: IPGRI, 1985. 100 p.

DELGADO, L.F.; BARBEDO, C.J. Tolerância à dessecação de sementes de Eugenia. Pesquisa Agropecuária Brasileira, Brasília, v.42, n.2, p.265272, 2007.

DONADIO, L.C.; MORO, F.V. Potential of brazilian Eugenia Myrtaceae - as ornamental and as a fruit crop. Acta Horticulturae, The Hague, v.632, p.65-68, 2004.

HELLMANN, M.E.; MELLO, J.I.O.; FIGUEIREDO-RIBEIRO, R.C.L.; BARBEDO, C.J. Tolerância ao congelamento de sementes de pau-brasil (Caesalpinia echinata $\mathrm{Lam}$ ) influenciada pelo teor de água inicial. Revista Brasileira de Botânica, São Paulo, v.29, n.1, p.93-101, 2006.

HONG, T.D.; ELLIS, R.H. A protocol to determine seed storage behavior Rome: IPGRI, 1996. 62 p. (Technical Bulletin, 1). 
JUSTO, C.F.; ALVARENGA, A.A.; ALVES, E.; GUIMARÃES, R.M.; STRASSBURG, R.C. Efeito da secagem, do armazenamento e da germinação sobre a micromorfologia de sementes de Eugenia pyriformis Camb. Acta Botânica Brasílica, São Paulo, v. 21, n.3, 2007.

KOHOMA, S.; MALUF, A.M.; BILIA, D.A.C.; BARBEDO, C. J. Secagem e Armazenamento de sementes de Eugenia brasiliensis Lam. (Grumixameira). Revista Brasileira de Sementes, Pelotas, v.28, n. 1, 2006.

LEONHARDT, C.; CALIL, A. C.; FIOR, C. S. Germinação de sementes de Myrcia glabra (O. Berg) D. Legrand e Myrcia palustris DC. - Myrtaceae armazenadas em câmara fria. Iheringia - Série Botânica, Porto Alegre, v.65, n.1, p.25-33, 2010.

MARCOS FILHO, J. Fisiologia de sementes de plantas cultivadas. Piracicaba: FEALQ, 2005. $495 \mathrm{p}$.

MASETTO, T. E.; FARIA, J. M. R.; DAVIDE, A. C.; SILVA, E. A. A. Desiccation tolerance and DNA integrity in Eugenia pleurantha O. Berg. (Myrtaceae) seeds. Revista Brasileira de Sementes, Viçosa, MG, v.30, n.1, p. $51-56,2008$.
MATO GROSSO DO SUL. Secretaria do Planejamento e Coordenação Geral. Atlas multireferencial. Campo Grande, 1990. 28 p.

PAMMENTER, N.W.; BERJAK, P. A review of recalcitrant seed physiology in relation to desiccationtolerance mechanisms. Seed Science Research, Cambridge, v.9, p. 13-37, 1999.

RANAL, M. A.; SANTANA, D. G. How and why to measure the germination process? Revista Brasileira de Botânica, São Paulo, v.29, n.1, p.1-11, 2006.

SCALON, S. P.Q.; SCALON FILHO, H.; RIGONI, M.R. Armazenamento e germinação de sementes de uvaia Eugenia uvalha Cambess. Ciência e Agrotecnologia, Lavras, v.28, n.6, p.1228-1234, 2004.

VENDRAME; SILVA, C., BILIA, D.A.C.; BARBEDO, C.J. Fracionamento e germinação em sementes de Eugenia. Revista Brasileira de Sementes, Viçosa,MG, v.27, n.1, p. 86-92, 2005.

YUYUAMA, K.; MENDES, N.B.; VALENTE, J.P. Longevidade de sementes de camu-camu submetidas a diferentes ambientes e formas de conservação. Revista Brasileira de Fruticultura, Jaboticabal, v. 33 , n. 2, p. 601-607, 2011 